\title{
Analyzing Reaction Times
}

\author{
Análisis de los tiempos de reacción
}

\author{
R. Harald Baayen \\ University of Alberta, \\ Petar Milin \\ University of Novi Sad, Serbia \\ University of Belgrade, Serbia
}

\begin{abstract}
Reaction times (RTs) are an important source of information in experimental psychology. Classical methodological considerations pertaining to the statistical analys is of RT data are optimized for analyses of aggregated data, based on subject or item means (c.f., Forster \& Dickinson, 1976). Mixed-effects modeling (see, e.g., Baayen, Davidson, \& Bates, 2008) does not require prior aggregation and allows the researcher the more ambitious goal of predicting individual responses. Mixed-modeling calls for a reconsideration of the classical methodological strategies for analysing rts. In this study, we argue for empirical exibility with respect to the choice of transformation for the RTs. We advocate minimal apriori data trimming, combined with model criticism. We also show how trial-to-trial, longitudinal dependencies between individual observations can be brought into the statistical model. These strategies are illustrated for a large dataset with a non-trivial random-effects structure. Special attention is paid to the evaluation of interactions involving fixed-effect factors that partition the levels sampled by random-effect factors.
\end{abstract}

Key words: Reaction times, distributions, outliers, transformations, temporal dependencies, linear mixed-effects modeling.

\section{RESUMEN}

El análisis de los tiempos de reacción (RTs) constituyen una valiosa herramienta en la psicología experimental. Las consideraciones metodológicas clásicas relacionadas al análisis estadístico de los datos obtenidos con los RT son optimizados para el análisis de datos agregados basados en los valores de la media (c.f., Forster \& Dickinson, 1976). La modelación de efectos mixtos (Baayen, Davidson, \& Bates, 2008), no requieren agregaciones a priori y permiten al investigador un resultado más robusto en la predicción de respuestas individuales. La modelación mixta reconsidera las estrategias metodológicas clásicas para el análisis de los RTs. En este estudio, nosotros apoyamos la flexibilidad empírica en lo que refiere a la escogencia del método para la transformación de los RTs. Adicionalmente nos aproximamos a un mínimo de datos parciales para criticar el modelo. Además, mostramos como la evaluación y el análisis de la dependencia entre las observaciones individuales pueden ser consideradas dentro el modelo estadístico. Estas estrategias se ilustran para un gran conjunto de datos sin efectos aleatorios simples en su estructura. Por último, se presta especial atención a la evaluación de las interacciones que contienen los efectos mixtos que particionan los niveles de muestreo por factores de efectos aleatorios.

Palabras clave: Identidades masculinas, patriarcado, violencia intrafamiliar.

\footnotetext{
Artículo recibido/Article received: Julio , 2010/July, 2010, Artículo aceptado/Article accepted: Septiembre, 2010/September, 2010 Dirección correspondencia/Mail Address:

R. Harald Baayen, Department of Linguistics, University of Alberta, 4-55 Assiniboia Hall Edmonton T6G 2E5, Canada, Email: baayen @ ualberta.ca

Petar Milin, Department of Psychology, Faculty of Philosophy, University of Novi Sad, Email: pmilin@ ff.uns.ac.rs
}

INTERNATIONAL JOURNAL OF PSYCHOLOGICAL RESEARCH esta incluida en PSERINFO, CENTRO DE INFORMACION PSICOLOGICA DE COLOMBIA, OPEN JOURNAL SYSTEM, BIBLIOTECA VIRTUAL DE PSICOLOGIA (ULAPSY-BIREME), DIALNET y GOOGLE SCHOLARS. Algunos de sus articulos aparecen en SOCIAL SCIENCE RESEARCH NETWORK y está en proceso de inclusion en diversas fuentes y bases de datos internacionales. INTERNATIONAL JOURNAL OF PSYCHOLOGICAL RESEARCH is included in PSERINFO, CENTRO DE INFORMACIÓN PSICOLÓGICA DE COLOMBIA, OPEN JOURNAL SYSTEM, BIBLIOTECA VIRTUAL DE PSICOLOGIA (ULAPSY-BIREME ), DIALNET and GOOGLE SCHOLARS. Some of its articles are in SOCIAL SCIENCE RESEARCH NETWORK, and it is in the process ofinclusion in a variety of sources and international databases. 
Reaction time (RT), also named response time or response latency, is a simple and probably the most widely used measure of behavioural response in time units (usually in milliseconds), from presentation of a given task to its completion. Chronometric methods that harvest RTs have played an important role in providing researchers in psychology and related fields with data constraining models of human cognition. In 1868, F. C. Donders ran a pioneer experiment in psychology, using for the first time RTs as a measure of behavioural response, and proved existence of the three types of RTs, differing in latency length (Donders, 1868/1969). Since that time psychologists (c.f., Luce, 1986, etc.) agree that there exist: simple reaction times, obtained in experimental tasks where subjects respond to stimuli such as light, sound, and so on; recognition reaction times, elicited in tasks with two types of stimuli, one to which subjects should respond, and the other which serve as distractions that should be ignored (today, this task is commonly referred to as a go/no-go task); and choice reaction times, when subjects have to select a response from a set of possible responses, for instance, by pressing an letter-key upon appearance of a letter on the screen. In addition, there are many others RTs which can be obtained by combining three basic experimental tasks. For example, discrimination reaction times are obtained when subjects have to compare pairs of simultaneously presented stimuli and are requested to press one of two response buttons. This type of RT represents a combination of a recognition and a choice task. Similarly, decision reaction time is a mixture of simple and choice tasks, having one stimulus at a time, but as many possible responses as there are stimulus types.

From the 1950s onwards, the number of experiments using RT as response variable has grow continuously, with stimuli typically obtained from either the auditory or visual domains, and occasionally also from other sensory domains (see for example one of the pioneering study by Robinson, 1934). Apart from differences across sensory domains, there are some general characteristics of stimuli that affect RTs. First of all, as Luce (1986) and Piéron (1920) before him concluded, RT is a negatively decelerating function of stimulus intensity: the weaker the stimulus, the longer the reaction time. After the stimulus has reached a certain strength, reaction time becomes constant. To model such nonlinear trends, modern regression offers the analyst both parametric models (including polynomials) as well as restricted cubic splines (Harrell, 2001; Wood, 2006).

Characteristics of the subjects may also influence RTs, including age, gender, handedness (c.f., MacDonald, Nyberg, Sandblom, Fischer, \& Backman, 2008; Welford, 1977, 1980; Boulinguez \& Barthélémy, 2000). An example is shown in Figure 1 for visual lexical decision latencies for older and younger subjects (see Baayen, Feldman, \& Schreuder, 2006; Baayen, 2010, for details ).
Finally, changes in the course of the experiment may need to be taken into account, such as the level of arousal or fatigue, the amount of previous practice, and so called trial-by-trial sequential effects - the effect of a given sequence of experimental trials (c.f., Broadbent, 1971; Welford, 1980; Sanders, 1998).

In the present paper we highlight some aspects of the analysis of chronometric data. Various guidelines have been proposed, almost always in the framework of factorial experiments in which observations are aggregated over subjects and/or items (Ratcliff, 1979; Luce, 1986; Ratcliff, 1993; Whelan, 2008). In this paper, we focus on data analysis for the general class of regression models, which include analys is of variance as a special case, but also cover multiple regression and analysis of covariance (see Van Zandt, 2000, 2002; Rouder \& Speckman, 2004; Rouder, Lu, Speckman, Sun, \& Jiang, 2005; Wagenmakers, van der Maas, \& Grasman, 2008, for a criticism and remedies of current practice). We address the analys is of RTs within the framework of mixed-effects modeling (Baayen et al., 2008), focusing on the consequences of this new approach for the classical methodological guidelines for responsible data analys is.

Figure 1. Older subjects (grey) have longer response latencies in visual lexical decision than younger subjects (black), with a somewhat steeper slope for smaller word frequencies ('stimulus intensity'), and a smaller frequency at which the effect of stimulus intensity begins to level o_. The nonlinearity was modeled with a restricted cubic spline with 5 knots.

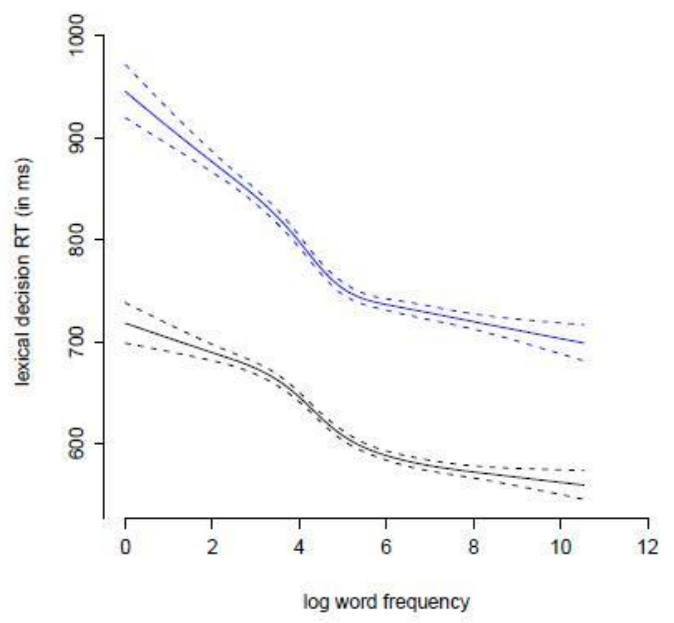

\section{Methodological concerns in reaction time data analysis}

Methodological studies of the analysis of reaction times point out at least two important violations of the preconditions for analysis of variance and regression. First, distributions of RTs are often positively skewed, violating 
International Journal of Psychological Research, 2010. Vo. 3. No. 2.

ISSN impresa (printed) 2011-2084

ISSN electrónica (electronic) 2011-2079

the normality assumption underlying the general linear model. Second, individual response latencies are not statistically independent - a trial-by-trial sequential correlation is present even in the most carefully controlled conditions. Additionally, and in relation to the first point, empirical distributions may be characterized by overly influential values that may distort the model fitted to the data. We discuss these issues in turn.

\section{Reaction time distributions}

There is considerable variation in the shape of the reaction time distributions, both at the level of individual subjects and items, and at the level of experimental tasks. Figure 2 illustrates micro-variation for a selection of items used in the visual lexical decision study of Milin, Filipovic Durdevic, and Moscoso del Prado Martín (2009). For some words, the distribution of RTs is roughly symmetric (e.g., \zid" /wall/, \trag" /trace/, and \drum"/road/). Other items show outliers (e.g., Iplod", /agreement/, and lugovor", /contract/). For most items, there is a rightward skew, but occasionally a left skew is present (lbrod", /ship/).

While modern visualization methods reveal considerable distributional variability (for an in depth discussions of individual RT distributions consult Van Zandt, 2000, 2002), older studies have sought to characterize reaction time distributions in more general terms as following an Ex-Gaussian (the convolution of normal and exponential distributions), an inverse-Gaussian (Wald), a log-normal, or a Gamma distribution (see, e.g., Luce, 1986; Ratcliff, 1993). Figure 3 illustrates the problems one encounters when applying these proposals for the reaction times in visual lexical decision elicited from 16 subjects for 52 Serbian words. With correlation between observed and expected quantiles we can certify that the Wald's distribution (the Inverse Gaussian) seems to fit the data the best: $r=-0,997(t 801=-387,43, p=0)$. The Ex-Gaussian distribution closely follows: $r=0.985(t 801=163.1, p=0)$, while the Log-normal and the Gamma distributions provide somewhat weaker fits: $r=0.984(t 801=151.45, p=0$ and $r=0.965$ ( $t 801=$ $104.89, p=0$ ), respectively.

Although Figure 3 might suggest the inverse normal distribution is the optimal choice, the relative goodness of fit of particular theoretical models varies across experimental tasks, however. To illustrate this point, we have randomly chosen one thousand RTs from three priming experiments using visual lexical decision, sentence reading and word naming. Figure 4 indicates that the Inverse Gaussian provides a better fit than the Log-Normal for the RTs harvested from the lexical decision experiment, just as observed for lexical decision in Figure 3. However, for sentence reading, the Log-Normal outperforms the Inverse Gaussian, while both theoretical models provide 14
Baayen, R.H., Milin, P.(2010). Analyzing Reaction Times. International Joumal of Psychological Research, 3(2), 12-28.

equally good fits for the naming data, where even the Gamma distribution approaches the same level of goodness of fit $(r=0: 995)$.

Figure 2. Estimated densities for the distributions of reaction times of selected items in a visual lexical decision experiment.

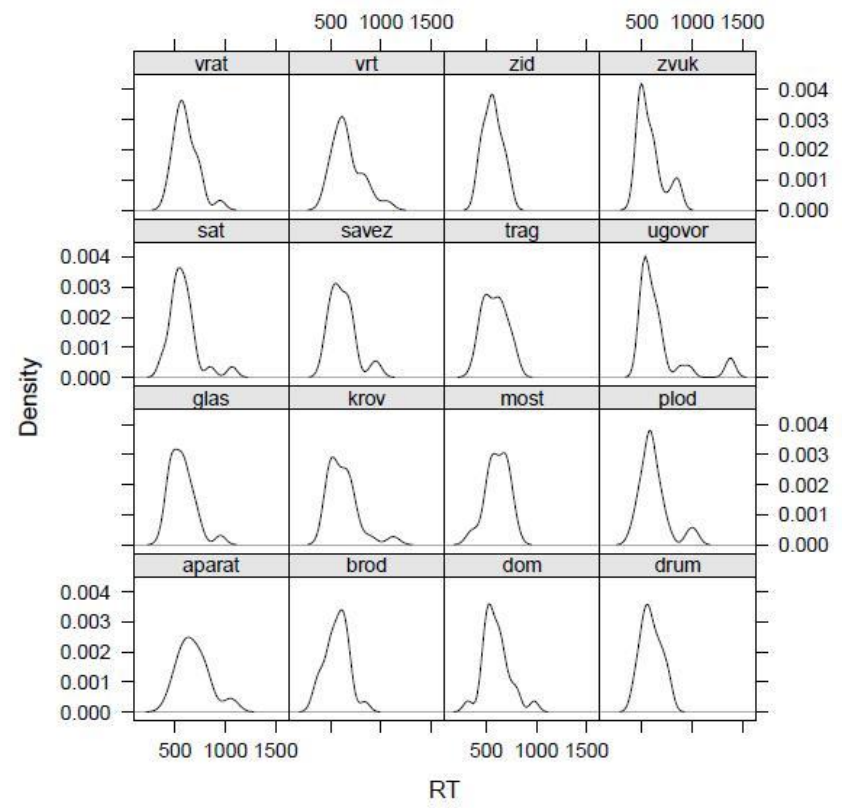

Figure 3. Goodness of fit offour theoretical distributions to response latencies in visual lexical decision.
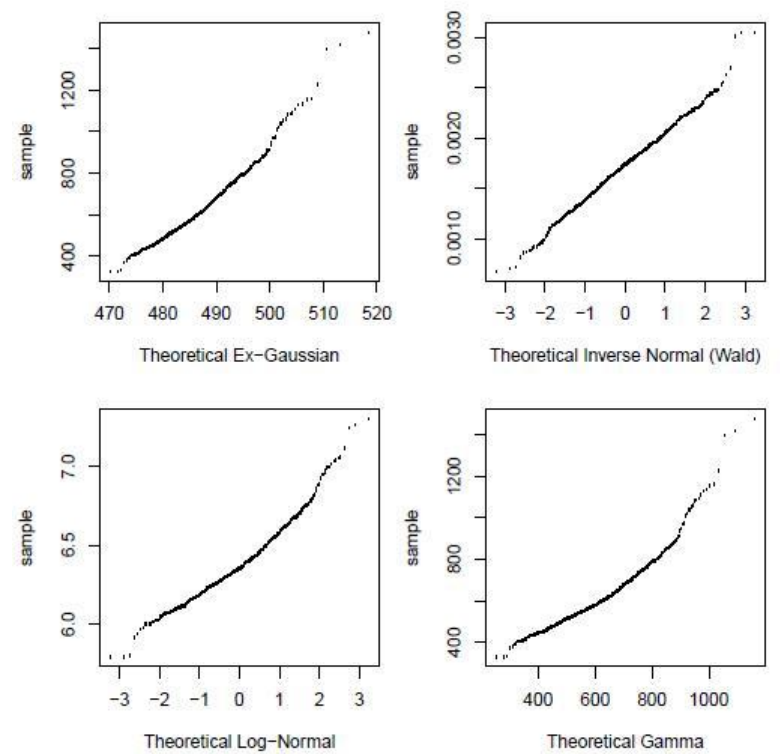

Thus, it is an empirical question which theoretical model provides the best approximation for one's data. Two International Journal of Psychological Research 
considerations are relevant at this stage of the analysis. First, in analyses aggregating over items to obtain subject means, or aggregating over subjects to obtain item means, simulation studies suggest that the Inverse Gaussian may outperform the Log-Normal Ratcliff (1993). Given the abovementioned variability across subjects, items, and tasks, it should be kept in mind that this superiority may be specific to the assumptions built into the simulations assumptions that may be more realistic for some subjects, items, and tasks, than for others. The Ex-Gaussian distribution (Luce, 1986) is a theoretically interesting alternative, and one might expect it to provide better fits given that it has one parameter more than Inverse Normal or Log-Normal. Nevertheless, our examples suggest it is not necessarily one's best choice - the power provided by this extra parameter may be redundant. Of course, for models with roughly similar goodness of fit, theoretical considerations motivating a given transformation should be given preference.

A second issue is more practical in nature. When RTs are transformed, a fitted general linear model provides coefficients and fitted latencies in another scale than the millisecond time scale. In many cases, it may be sufficient to report the data on the transformed scale. However, it may be necessary or convenient to visualize partial effects on the original millisecond scale, in which case the inverse of the transformation is required. This is no problem for the LogNormal and the Inverse-Gaussian transforms, but backtransforming an Ex-Gaussian is far from trivial, as it requires Fourier transformations and division in the Fourier domain, or Maximum Entropy deconvolution (see, e.g., Wagenmakers et al., 2008; Cornwell \& Evans, 1985; Cornwell \& Bridle, 1996; Beaudoin, 1999, and references cited there).

\section{Outliers}

Once RTs have been properly transformed, the question arises of whether there are atypical and potentially overly influential values that should be removed from the data set. Strictly speaking, one should differentiate between two types of influential points: the outliers have acceptable value of the linput" variable while the value of the Iresponse" is either too large or too small; the extreme values are notably different from the rest of the linput" values. Thus, influential values are those outliers or extreme values which essentially alter the estimates, the residuals and/or the fitted values (more about these issues can be found in Hocking, 1996). By defining RT as the measure of behavioural response we implied that it may contain outliers and can be affected by extreme values. The question is how to diagnose them and to put them under explicit control.
Figure 4. Variation in goodness of fit of the LogNormal and Inverse-Normal distributions across three experimental tasks.
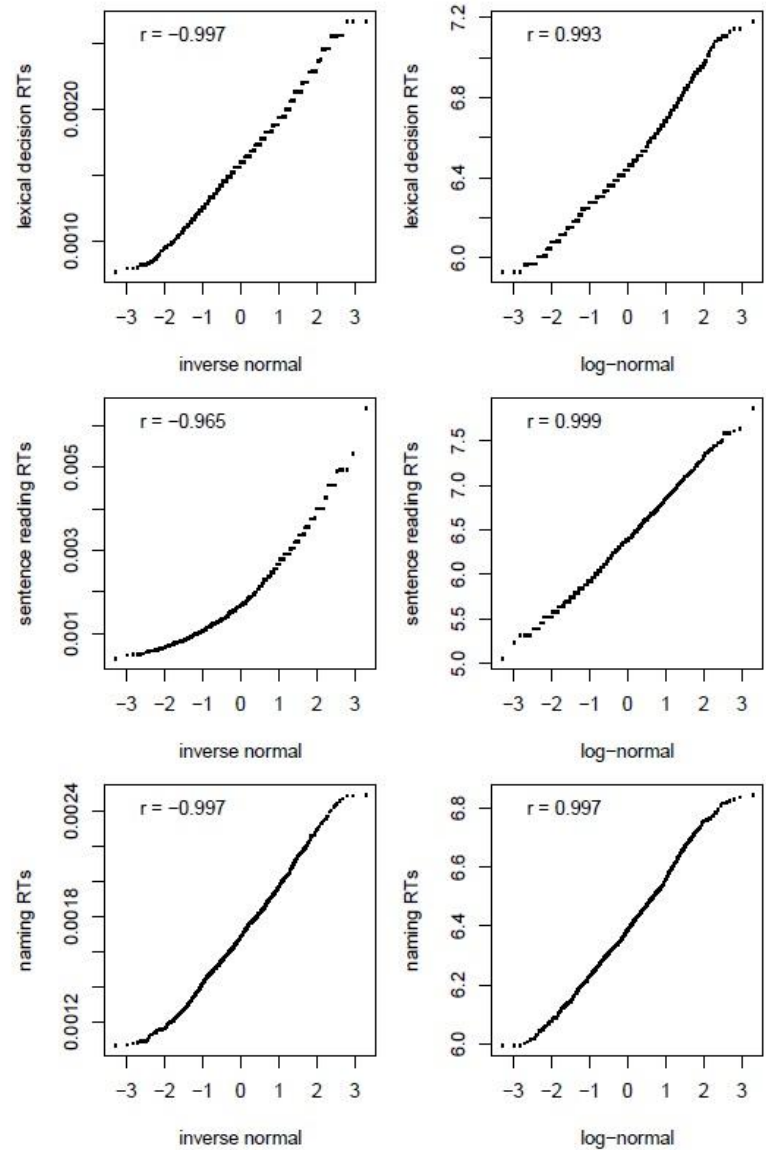

First of all, physically impossibly short RTs (button presses within $5 \mathrm{~ms}$ of stimulus onset) and absurdly long latencies (exceeding 5 seconds in a visual lexical decision task with unimpaired undergraduate subjects) should be excluded. After that, more subtle outliers may still be present in the cleaned data, however. Ratcliff (1993) distinguishes between two kinds of outliers, short versus long response outliers. According to Ratcliff, short outliers Istand alone" while long outliers \hide in the tail" (Ratcliff, 1993, p. 511). Even if long outliers are two standard deviations above the mean, they may be difficult to locate and isolate. Unfortunately, even a single extreme outlier can considerably increase mean and standard deviation (Ratcliff, 1979).

There are two complementary strategies for outlier treatment that are worth considering. Before running a statistical analysis, the data can be screened for outliers. However, after a model has been fitted to the data, model criticism may also help identify overly influential outliers. A-priori screening is regular practice in psycholinguistics. 
International Journal of Psychological Research, 2010. Vo. 3. No. 2. ISSN impresa (printed) 2011-2084

ISSN electrónica (electronic) 2011-2079

By contrast, model criticism seems to be undervalued and underused.

A-priori screening for outliers is a widely accepted practice in traditional by-subject and by-item analyses. It simply removes all observations that are at a distance of more than two standard deviations from the mean of the distribution. Nevertheless, there is a risk to this procedure. If the effect Vlives" in the right tail of the distribution, as Luce (1986) discussed pointing out that the decision itself may behave as exponential - right-hand component of the distribution, then removing longer and long latencies may in fact reduce or cancel out the effect in the statistical analysis (see Ratcliff, 1993). Conversely, if the effect is not in the tail, then removing long RTs increases statistical power (c.f., Ratcliff, 1993; Van Zandt, 2002). For analyses using data aggregated over items or subjects, Ratcliff's advice is that cutoffs should be selected as a function of the proportion of responses removed. Up to $15 \%$ of the data can be removed, but only if there is no thick right tail, in which case no more than $5 \%$ of the data should be excluded.

We note here that much depends on whether outliers are considered before or after transforming the reaction times. Data points that look like outliers before the transformation is applied may turn out to be normal citizens after transformation. More generally, if the precondition of normality is well met, then outlier removal before model fitting is not necessary.

In analyses requiring aggregating over items and/or subjects, the question arises whether in the presence of outliers, the mean is the best measure of central tendency. It has been noted that as long as the distribution is roughly symmetrical, the mean will be an adequate measure of central tendency (c.f., Keppel \& Saufley Jr., 1980; Sirkin, 1995; Miller, Daly, Wood, Roper, \& Brooks, 1997). For non-symmetrical distributions, however, means might be replaced by medians (see, for example, Whelan, 2008). The median is much more insensitive to the skew of the distribution, but at the same time it can be less informative. Van Zandt (2002) showed that the median is biased estimator of population central tendency when the population itself is skewed, although this bias is relatively small for samples of $N \geq 25$. At the same time, the results of Ratcliff (1993)'s simulations showed that the median of the untransformed RTs has much higher variability compared to the harmonic mean $H=n \quad \eta_{i=1} \frac{1}{x_{i}}$. Unfortunately, the harmonic mean is more sensitive to outliers and cutoffs then the median. If the noise is equally spread out across experimental conditions and if an appropriate cutoff is used, then the harmonic mean would be a beter choice than the median, while the median will be
Baayen, R.H., Milin, P. (2010). Analyzing Reaction Times. International Joumal of Psychological Research, 3(2), 12-28.

more stable if outliers are not distributed proportionally across conditions.

While a-priori "agressive" screening for outliers is defendable for by-subject and by-item ANOVAs, critically depending on means aggregated over subjects or items, the need for optimizing central values before data analysis disappears when the analysis targets the more ambitious goal of predicting individual RTs using mixed-effects models with subjects and items as crossed random-effect factors. The mixed-modeling approach allows for mild apriori screening for outliers, in combination with model criticism, a second important procedure for dealing with outliers.

In the remainder of this study, we provide various code snippets in the open source statistical programming environment $\mathrm{R}$ (http://www.r-project.org/), which provides a rich collection of statistical tools. The dataset that we use here for illustrating outlier treatment is available in the language package as lexdec. Visual lexical decision latencies were elicited for 21 subjects responding to 79 concrete nouns. Inspection of quantilequantile plots suggests that a Inverse-Gaussian transformation is optimal. Quantile-quantile plots for the individual subjects are brought together in the trellis shown in Figure 5.

> qqmath ( RTinv | Subject, data = lexdec)

The majority of subjects come with distributions that do not depart from normality. However, as indicated by Shapiro tests for normality, there are a few subjects that require further scrutiny, such as subjects A3 and M1.

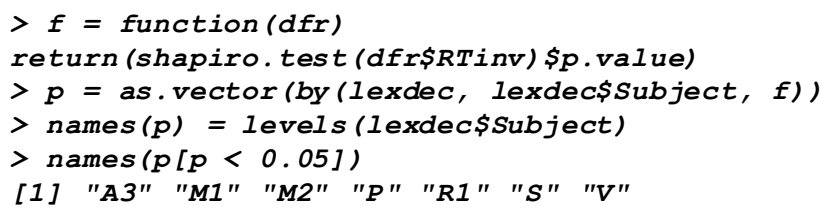

Figure 6 presents the densities for the four subjects for which removal of a few extreme outliers failed to result in normality. The two top leftmost panels (subjects $\mathbf{A} 3$ and M1) have long and thin left tails due to a few outliers, but their removal results in clearly bimodal distributions, as can be seen in the corresponding lower panels. The density for subject M2 shows a leftward skew without outliers, but after removing some highest and lowest values distribution gets two modes of almost equal hight. Conversely, the density for subject $\mathrm{V}$ is again bimodal before, and gently skewed to the left after the removal.

Figure 5. By-subject quantile-quantile plotsfor the inversetransformed reaction times (visual lexical-decision). 


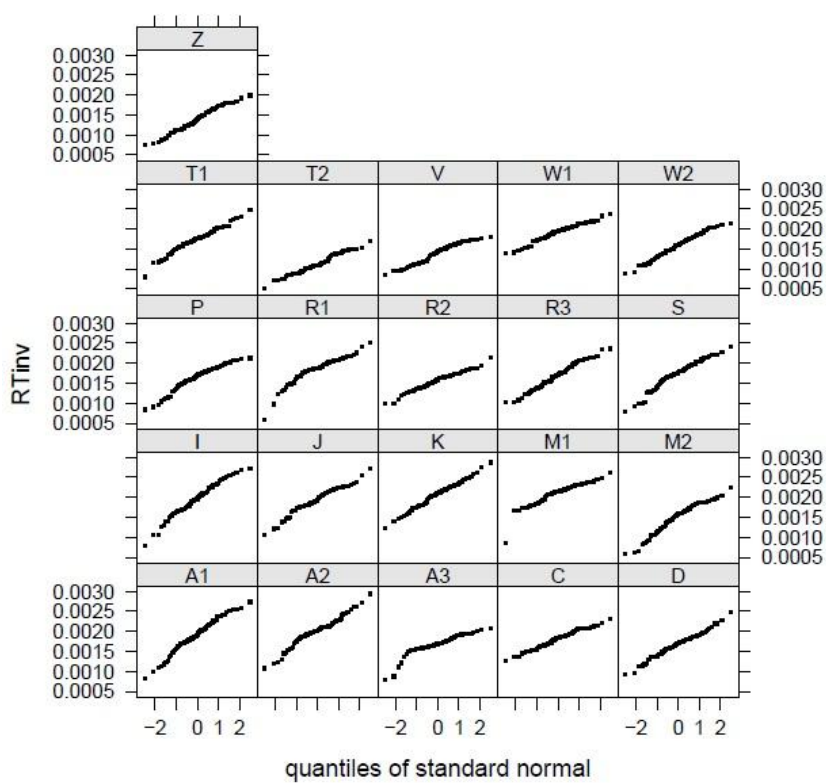

Minimal trimming for subjects A3, M1， P, R1, $\mathbf{S}$ resulted in a new data frame (the data structure in $\mathbf{R}$ for tabular data), which we labeled lexdec2. With the trimming we lost $2.7 \%$ of the original data, or 45 data points. For comparison, we also created a data frame with all data points removed that exceeded 2 standard deviations from either subject or item means (lexdec3). This data frame comes with a loss of 134 datapoints $(8.1 \%$ of the data). These data frames allow us to compare models with different outlier-handling strategies. (In what follows, we multiplied the inversely transformed RTs by -1000 so that coefficients will have the same sign as for models fitted to the untransformed latencies, at the same time avoiding very small values and too restricted range for the dependent variable.)

A model fitted to all data, without any outlier removal:

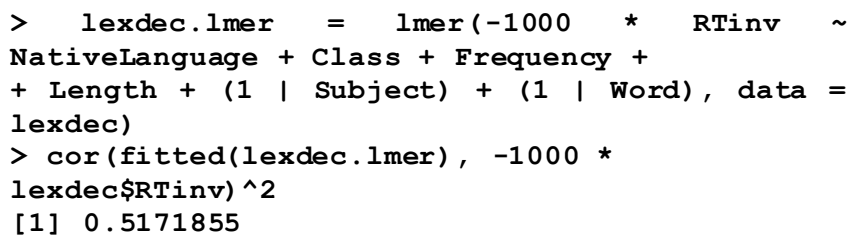

performs less well in terms of $R^{2}$ than a model with the traditional aggressive a-priori data screening:

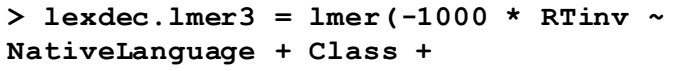

Figure 6. Density plots for subjects for which the InverseGaussian transform does not result in normality (visual lexical-decision). Upper panels represent untrimmed data,
Baayen, R.H., Milin, P. (2010). Analyzing Reaction Times. International Journal of Psychological Research, 3(2), 12-28.

while lower panels depict the distributions for two subjects after minimal trimming.
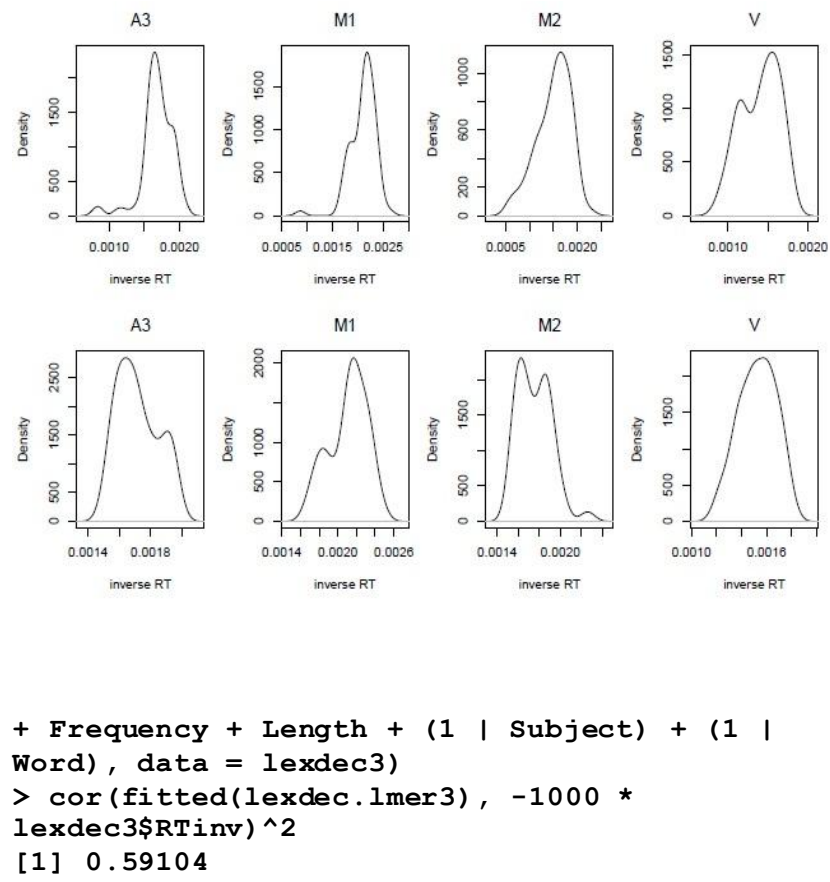

while mild initial data screening results in a model with an intermediate $R^{2}$ :

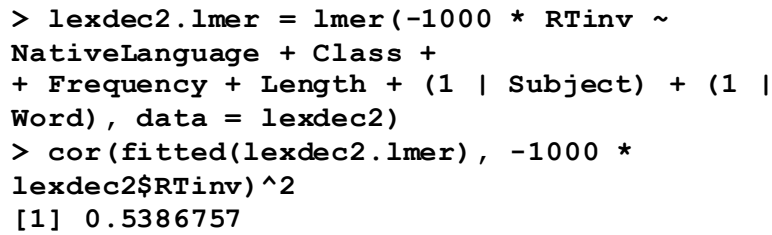

Inspection of the residuals of this model (lexdec2.lmer) shows that it is stressed, and fails to adequately model longer response latencies, as can be seen in the lower left panel of Figure 7. To alleviate the stress from the model, we remove data points with absolute standardized residuals exceeding 2.5 standard deviations:

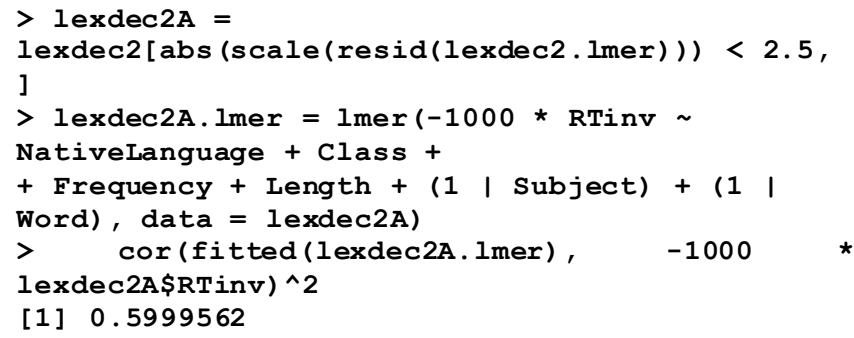

Figure 7. Quantile-quantile plots for the models with different strategies of outlier removal. 


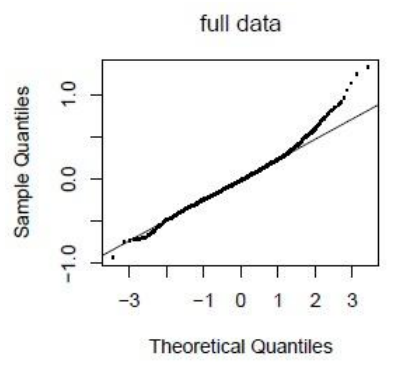

minimal a-priori trimming, no model criticism

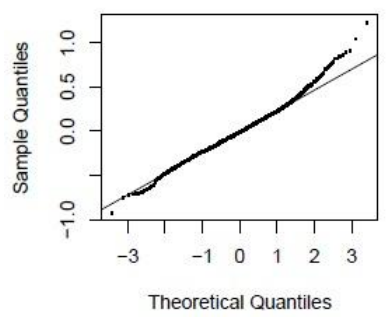

agressive a-priori trimming

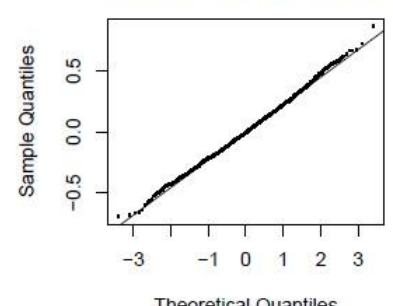

minimal trimming and model criticism

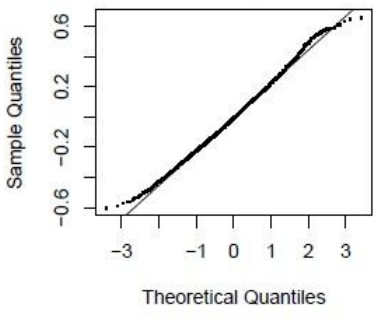

The last model, which combines both mild initial data screening and model criticism, outperforms all other models in terms of $R^{2}$. Compared to the traditional aggressive data trimming procedure, it succeeds in doing so by achieving reasonable closeness to normality, while removing fewer data points (82 versus 134). The quantilequantile plot for the residuals of this model is shown in the lower right panel of Figure 7.

What this example shows is that a very good model can be obtained with minimal a-priori screening, combined with careful post-fitting model criticism based on evidence that the residuals of the fitted model do not follow a normal distribution. If there is no evidence for stress in the model fit, then removal of outliers is not necessary and should not be carried out. Furthermore, there are many diagnostics for identifying overly influential outliers, such as variance inflation factors and Cook's distance, which may lead to a more parsimoneous removal of data points compared to the procedure illustrated in the present paper. It simply errs on the conservative side, but allows the researcher to quickly assess whether or not an effect is carried by the majority of data points.

We note here that it may well be that the data points removed due to model criticism reflect decision processes distinct from the processes subserving lexical retrieval, which therefore may require further scrutiny when these decision processes are targeted by the experiment.

Figure 8. Autocorrelation functions for the subjects in a present-to-past word naming study. Grey horizontal lines represent the upper bound of an approximate $95 \%$ confidence interval.
Baayen, R.H., Milin, P.(2010). Analyzing Reaction Times. International Joumal of Psychological Research, 3(2), 12-28.

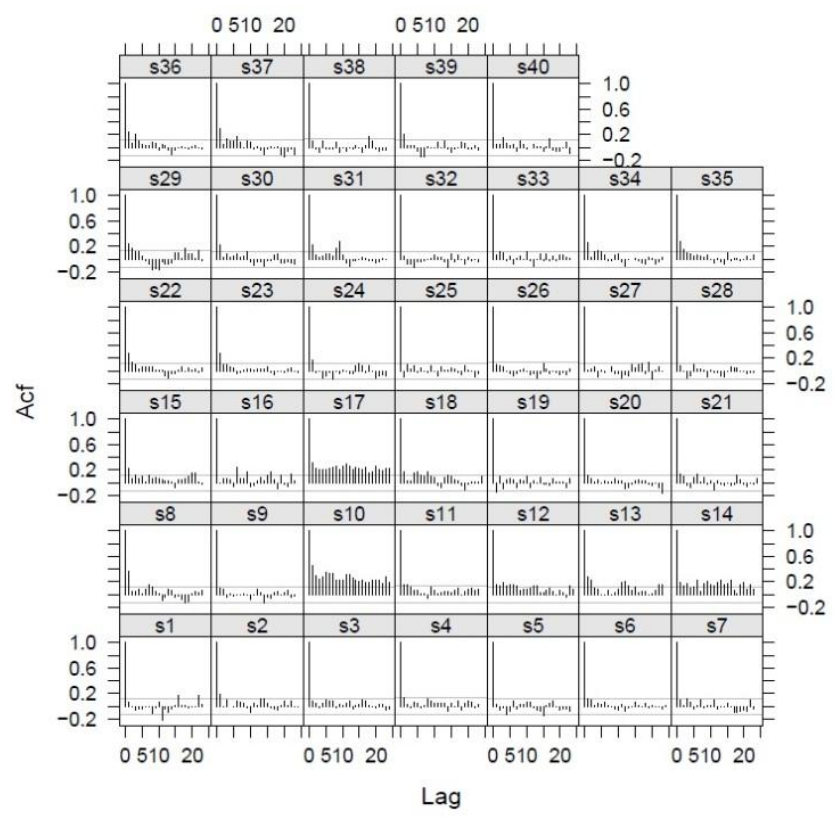

Temporal dependencies

The third is sue that needs to be addressed when modeling reaction times is the temporal dependencies that exist between successive trials in many experiments (Broadbent, 1971; Welford, 1980; Sanders, 1998; Taylor \& Lupker, 2001, etc.). Often, RTs at trial $t$ correlate with RT at trial $t=i$, for small $i$. This temporal auto-dependency can be quantitatively expressed in terms of the autocorrelation coefficient. In the case of reaction times, there often is an inverse relationship of the distance or lag between predecessor/successor RT and the coefficient of autocorrelation: the longer the lag the weaker the autocorrelation.

To illustrate the phenomenon of trial-by-trial dependencies, we consider data from a word naming study on Dutch (Tabak, Schreuder, \& Baayen, 2010a), in which subjects were shown a verb in the present (or paste) tense and were requested to name the corresponding past (or present) tense form. Figure 8 shows the autocorrelation functions for the time series of RTs for each of the subjects, obtained by applying acf.fnc function from the language R package (version 1.0), which builds on the acf function from stats package in $\mathrm{R}$ and lattice graphics.

$>$ acf.fnc(dat, group $=$ "Subj", time = "Trial", $\mathbf{x}=$ "RT", plot = TRUE)

Many subjects show significant autocorrelations at short lags, notably at a lag of one. For some subjects, such as s10 and s17, significant autocorrelations are found across a much wider span of lags. As the generalized linear model (and special cases such as analys is of variance) build International Journal of Psychological Research 
on the assumption of the independence of observations, corrective measures are required. In what follows, we illustrate how this temporal correlation can be removed by taking as example results from subject s10. A regression model is fitted to this subject's responses, with a logtransform for the naming latencies, using a quadratic (nonorthogonal) polynomial for word frequency, and with two covariates to bring temporal dependencies under control: TRIAL and the PRECEDING RT. The coefficients of the fitted model are listed in Table 1.

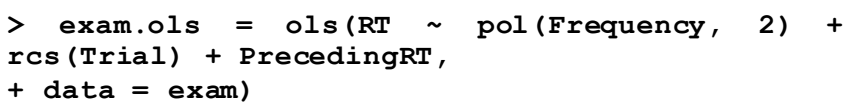

The first temporal control, Trial, represents rankorder of a trial in its experimental sequence. Since trials are usually presented to each participant in different, (pseudo)randomized sequence, rank-ordering is unique between participants. In general, this control covariate models the large-scale flow of the experiment, representing learning (latencies becoming shorter) or fatigue (latencies becoming longer as the experiment proceeds). For the present subject (s10), responses were executed faster as the experiment proceeded, suggesting adaptation to the task (upper left panel of Figure 9). It is worth noting that the trial number in an experimental session may enter into an interaction with one or more critical predictors, as in the eye-tracking study of Bertram, Kuperman, and Baayen (2010). Figure 9 indicates that the present learning effect is greater in magnitude than the effect of frequency.

The second temporal control covariate is the latency at the preceding trial (PRECEDING RT). For the initial trial, this latency is imputed from the other latencies in the time series (often as mean reaction time). The current latency and the preceding latency are highly correlated $(r=0: 46, t 250=8: 13, p \ll 0,0001$. The effect size of PRECEDING RT is substantial, and greater than the effect size of FREQUENCY (see Figure 9). Studies in which this predictor has been found to be significant range from speech production (picture naming, Tabak, Schreuder, \& Baayen, 2010b), and speech comprehension (auditory lexical decision, Baayen, Wurm, \& Aycock, 2007; Balling \& Baayen, 2008), to reading (visual lexical decision, De Vaan, Schreuder, \& Baayen, 2007; Kuperman, Schreuder, Bertram, \& Baayen, 2009; and progressive demasking, Lemhoefer et al., 2008).

A model with just FREQUENCY as predictor has an R-squared of 0.027. By adding Trial as predictor, the Rsquared improves to 0.288. Including both TRIAL and PRECEDING RT results in an R-squared of 0.334. The lower panels of Figure 9 illustrate that including Trial as predictor removes most of the autocorrelation at later lags, but a significant autocorrelation persists at lag 1 . By including
Preceding RT as predictor, this autocorrelation is also removed.

Across many experiments, we have found that including variables such as TRIAL and PRECEEDING RT in the model not only avoids violating the assumptions of linear modeling, but also helps improving the fit and clarifying the role of the predictors of interest (see, e.g., De Vaan et al., 2007).

Table 1: Coefficients of an ordinary least-squares regression model fitted to the naming latencies of subject $19 s$.

\begin{tabular}{lrrrr}
\hline & Value & Std. Error & $\mathrm{t}$ & $\mathrm{p}$ \\
\hline Intercept & 5.6850 & 0.4730 & 12.0179 & 0.0000 \\
$\begin{array}{l}\text { Frequency } \\
\text { (linear) }\end{array}$ & -0.1657 & 0.0610 & -2.7179 & 0.0070 \\
$\begin{array}{l}\text { Frequency } \\
\text { (quadratic) }\end{array}$ & 0.0088 & 0.0036 & 2.4282 & 0.0159 \\
Trial & -0.0013 & 0.0002 & -6.3415 & 0.0000 \\
Preceding RT & 0.2570 & 0.0601 & 4.2777 & 0.0000 \\
\hline
\end{tabular}

An example of mixed-effects modeling

Mixed-effects models offer the researcher the possibility of analyzing data with more than one randomeffect factor - a factor with levels sampled from some large population. In psycholinguistics, typical random-effect factors are subjects (usually sampled from the undergraduate students that happen to be enrolled at one's university) and items (e.g., syllables, words, sentences). Before the advent of mixed-models, data with repeated measurements for both subjects and items had to be analyzed by aggregating over items to obtain subject means, aggregating over subjects to obtain item means, or both (see,e.g., Clark, 1973; Forster \& Dickinson, 1976; Raaijmakers, Schrijnemakers, \& Gremmen, 1999, and references cited there). mixed-models obviate the necessity of prior averaging, and thereby offer the researcher the far more ambitious goal to model the individual response of a given subject to a given item. Importantly, mixed-models offer the possibility of bringing sequential dependencies, as described in the preceding section, into the model specification. They also may offer a small increase in power, and better protection against Type II errors. In what follows, we discuss, a large dataset illustrating some of the novel possibilities offered by the mixed-modeling framework building on prior introductions (here we build on prior introductions given by Pinheiro \& Bates, 2000; Baayen et al., 2008; Jaeger, 2008; Quené \& Bergh, 2008, etc.). Analyses are run with the lme4 package for $\mathbf{R}$ (Bates \& Maechler, 2009).

Figure 9. Partial effects of FREQUENCY, Trial, and PRECEDING RT (upper panels), and auto-correlation 
International Journal of Psychological Research, 2010. Vo. 3. No. 2.

ISSN impresa (printed) 2011-2084

ISSN electrónica (electronic) 2011-2079

functions for the residuals of three regression models fitted to the data of subject 19s (left: FREQUENCY as only predictor, center: FREQUENCY and TRIAL, right: FREQUENCY, TRIAL and PRECEDING RT.

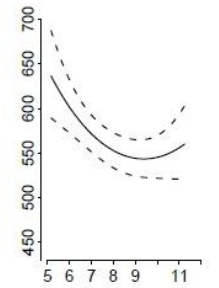

Frequency

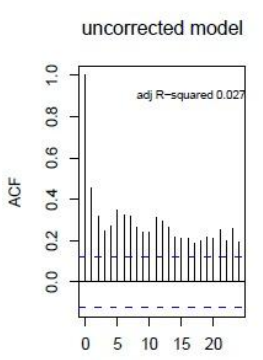

Lag

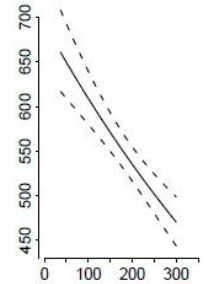

Trial

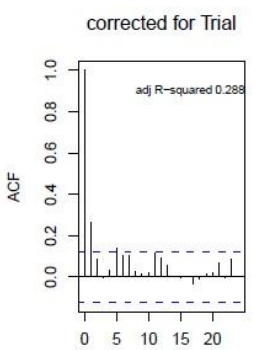

Lag

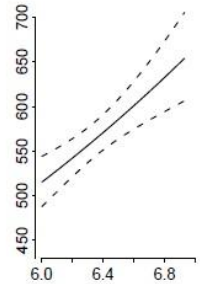

PrecedingRT corrected for Trial

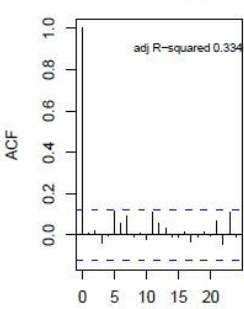

Lag and Preceding RT

The data

The dataset comprises 275996 self-paced reading latencies elicited through a web interface from 326 subjects reading 2315 words distributed over 87 poems in the anthology of Breukers (2006). Subjects included students in an introductory methods class, as well as their friends and relatives. For fixed-effect factors, we made use of contrast coding, as this allows for a more straightforward interpretation of interactions involving factors and covariates. We made use of five kinds of predictors.

1. Properties of the words: word length (WORDLENGTH), the (log-transformed) long-term frequency of the word, estimated from the CELEX lexical database (WORDFORM-FREQUENCY), the word's number of meanings, estimated from the number of synsets in the Dutch WordNet in which it is listed (SYNSETCOUNT), the word's morphological family size - the number of words in which it forms a constituent (FAMILYSIZE), the word's inflectional entropy, specifying an information load of its inflectional paradigm (INFLECTIONALENTROPY), the word's count of morphemes (NMORPHEMES), and whether the word is a function word (ISFUNCTIONWORD, with reference level 'FALSE'). (For the theoretical framework guiding the selection of these predictors, see Baayen, 2007 and Milin, Kuperman, Kostic, \& Baayen, 2009.) Further predictors are the frequency of the word in the poem up to the point of reading (LOCALFREQUENCY), the
Baayen, R.H., Milin, P. (2010). Analyzing Reaction Times. International Joumal of Psychological Research, 3(2), 12-28.

frequency of the rhyme in the poem up to the point of reading (LOCALRHYMEFREQ), and the frequency of the word's onset up to the point of reading (LOCALONSETFREQ). Rhymes and onsets were calculated for the last and first syllables of the word, respectively. Onsets were defined as all consonants preceding the vowel of the syllable, and rhymes were defined as the vowel and all tautosyllabic following consonants. Note that these last three predictors are not available to analyses that crucially require aggregation over subjects and/or items.

Unsurprisingly, LOCALRHYMEFREQ and LOCALONSETFREQ enter into strong correlations with LOCALFREQUENCY $(r>0: 6)$. We therefore decorrelated LOCALRHYMEFREQ from LOCALFREQUENCY by regressing LOCALRHYMEFREQ on LOCALFREQUENCY and taking the residuals as new, orthogonalized, predictor. The same procedure was followed for LOCALONSETFREQ. The two residualized variables correlated well with the original measures ( $r=0.77$ for LOCALRHYMEFREQ and $(r=0.80$ for LOCALONSETFREQ). Thus, decorrelation was justified to control for the collinearity, but, moreover, it did not change the nature of the original predictors.

2. Properties of the lines of verse: the length of the sentence (SENTENCELENGTH), the position of the word in the sentence (POSITION, a fixed-effect factor with levels 'Initial', 'Mid', 'Final', with 'Initial' as reference level), whether the word was followed by a punctiation mark (PUNCTUATIONMARK, reference level 'FALSE'), and the number of words the reader is into the line (NUMBEROFWORDSINTOLINE).

3. Properties of the subject: AGE (ranging from 13 to 63, median 23), SEX (187 women, 142 men), HANDEDNESS (39 left handed, 290 right handed), and two variables elicited during a questionairre at the end of the experiment. This questionaire asked subjects to indicate (through a four-way multiple choice) how many poems they estimated reading on a yearly basis, this estimate was log-transformed (POEMSREADYEARLY). The time required to reach this choice was also recorded, and log-transformed (CHOICERT).

4. Longitudinal predictors: Trial, the number of words read at the point of reading (ranging from 1 to 1270), and Preceding RT, the self-paced reading latency at the preceding word. These two predictors are not available for analyses based on aggregated data as well.

5. Three random-effect factors: Subject, Word, and Poem. Note that we can include more than two random-effect factors if there are multiple kinds of 
International Journal of Psychological Research, 2009. Vo. 3. No. 2.

ISSN impresa (printed) 2011-2084

ISSN electrónica (electronic) 2011-2079

repeated measures in the dat; no separate $F_{1}, F_{2} F_{3}, \ldots, F_{n}$ tests need to be carried out.

\section{A model}

A stepwise variable selection procedure resulted in a model that is specified as follows, using the lmer function from lme4 package in $\mathrm{R}$ :

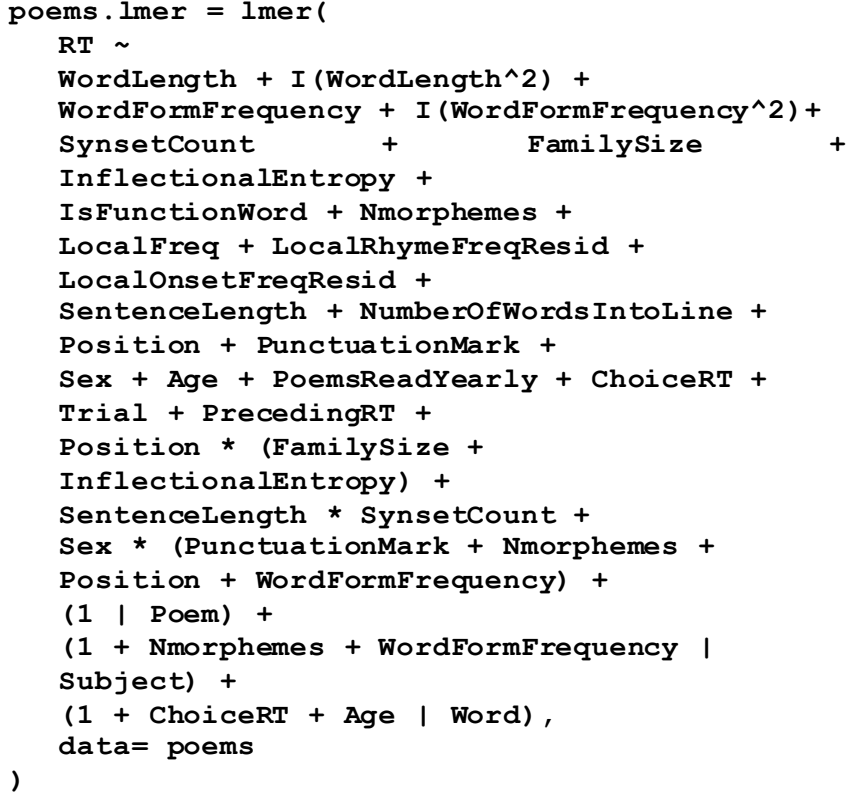

Main effects are listed separated by a plus sign, interactions are specified by an asterisk. Here, we used a quadratic polynomial for, e.g., the negative decelerating trend of WORDFORMFREQUENCY. We specified the terms for the linear component and the quadratic component (indicated by $\wedge^{\wedge}$ ) s separately in order to be able to restrict an interaction with SEX to the linear component.

Random-effect factors are specified between parentheses. The notation ( 1 | Poem) indicates that the model includes random intercepts for Poem. This allows for the possibility that some poems might be more dificult or more interesting to read, leadingto longer reaction times across all words in the poem and across all subjects. The notation $(1+$ Nmorphemes + WordFormFrequency | Subject) specifies a more interesting random-effects structure for the subjects. Not only do we have random intercepts for the subjects (indicated by the 1), we also have random slopes for the number of morphemes in the word (NMORPHEMES) as well as for WORDFORMFREQUENCY. Inclusion of these random slopes relaxes the assumption that the effect of NMORPHEMES or WORDFORMFREQUENCY would be identical acros s subjects. The same notation for the randomeffect factor WORD indicates that random intercepts and
Baayen, R.H., Milin, P. (2010). Analyzing Reaction Times. International Journal of Psychological Research, 3(2), 12-28.

random slopes for the subject's AGE and CHOICERT were required.

It is important to note here that random slopes for subjects pertain to properties of the words, and that the random slopes for word pertain to properties of the subjects. These notational conventions provide the analyst with flexible tools for tracing how the effects of properties of items vary across subjects, and how characteristics of subjects affect the processing of items.

Strictly speaking, the terminology of fixed versus random effects pertains to factors. However, in mixedmodeling terminology, covariates are often reported as part of the fixed-effects structure of the model. We shall follow this convention in the present paper. In what follows, we first discuss the coefficients for the fixed effects (fixedeffect factors and covariates), and then zoom into the random-effects structure of the model.

\section{Fixed-effects structure}

Table 2 lists the estimates for the intercept, the slopes, the contrast coefficients and their interactions in the fitted model. For the present large dataset, an absolute tvalue exceeding 2 is an excellent indicator of significance (see Baayen et al., 2008). A full discussion of this model is beyond the scope of the present paper. Here, we call attention to a few aspects that are of methodological interest.

First, it is noteworthy that the two coefficients with the largest absolute t-values are two control predictors that handle temporal dependencies: TRIAL and PRECEDINGRT. Their presence in the model not only helps satisfy to a better extent the independence assumption of the linear model, but also contribute to a more precise model with a smaller residual error. Simply stated, these predictors allow a more precise estimation of the contributions of the other, theoretically more interesting, predictors.

Second, our model disentangles the contributions of longterm frequency (as gauged by frequency of occurrence in a corpus) from the contribution of the frequency with which the word has been used in the poem up to the point of reading. Long-term frequency (WORDFORMFREQUENCY) emerged with a negative decelerating function, with diminishing facilitation for increasing frequencies. Shortterm frequency (LOCALFREQ) made a small but highly significant independent contribution. We find it remarkable that this short-term (i.e., episodic) frequency effect is detectable in spite of massive experimental noise. 
International Journal of Psychological Research, 2010. Vo. 3. No. 2.

ISSN impresa (printed) 2011-2084

ISSN electrónica (electronic) 2011-2079
Baayen, R.H., Milin, P. (2010). Analyzing Reaction Times. International Journal of Psychological Research, 3(2), 12-28.

Table 2: Estimated coefficients, standard errors, and t-values for the mixed-model fitted to the self-paced reading latencies elicited for Dutch poems.

\begin{tabular}{|c|c|c|c|}
\hline & Estimate & Std. Error & $\mathrm{t}$ value \\
\hline Intercept & 3.7877 & 0.0244 & 155.2758 \\
\hline WordLength & -0.0024 & 0.0031 & -0.7789 \\
\hline I(WordLength^2) & 0.0010 & 0.0002 & 4.7543 \\
\hline WordFormFrequency & -0.0240 & 0.0058 & -4.0971 \\
\hline $\mathrm{I}($ WordFormFrequency^2) & 0.0051 & 0.0018 & 2.8385 \\
\hline SynsetCount & 0.0240 & 0.0045 & 5.3294 \\
\hline Family Size & -0.0042 & 0.0013 & -3.1877 \\
\hline InflectionalEntropy & -0.0122 & 0.0027 & -4.4556 \\
\hline IsFunctionWordTRUE & 0.0055 & 0.0061 & 0.8920 \\
\hline Nmorphemes & 0.0005 & 0.0013 & 0.3923 \\
\hline LocalFreq & -0.0048 & 0.0004 & -11.7279 \\
\hline LocalRhy meFreqResid & 0.0029 & 0.0008 & 3.7343 \\
\hline LocalOnsetFreqResid & -0.0062 & 0.0007 & -8.5043 \\
\hline SentenceLength & -0.0016 & 0.0005 & -2.8406 \\
\hline NumberOfWordsIntoLine & 0.0029 & 0.0004 & 7.6266 \\
\hline Position $=$ Final & 0.0608 & 0.0061 & 9.8940 \\
\hline Position $=\mathrm{Mid}$ & -0.0621 & 0.0038 & -16.2994 \\
\hline PunctuationMark = TRUE & 0.1496 & 0.0031 & 48.8943 \\
\hline Sex $=$ Male & 0.0516 & 0.0149 & 3.4612 \\
\hline PoemsReadYearly & -0.0111 & 0.0060 & -1.8456 \\
\hline ChoiceRT & 0.0543 & 0.0087 & 6.2233 \\
\hline Trial & -0.0002 & 0.0000 & -73.1891 \\
\hline PrecedingRT & 0.3957 & 0.0017 & 234.5453 \\
\hline Family Size $:$ Position $=$ Final & 0.0028 & 0.0013 & 2.2295 \\
\hline Family Size $:$ Position $=$ Mid & 0.0035 & 0.0008 & 4.4843 \\
\hline InectionalEntropy $:$ Position $=$ Final & 0.0140 & 0.0027 & 5.1897 \\
\hline InectionalEntropy : Position $=\mathrm{Mid}$ & 0.0077 & 0.0021 & 3.7411 \\
\hline SynsetCount : SentenceLength & -0.0023 & 0.0004 & -5.7932 \\
\hline PunctuationMark = TRUE $:$ Sex $=$ Male & -0.0291 & 0.0040 & -7.3039 \\
\hline Nmorphemes : Sex $=$ Male & -0.0024 & 0.0013 & -1.9004 \\
\hline Position $=$ Final $:$ Sex $=$ Male & -0.0144 & 0.0044 & -3.2749 \\
\hline Position $=$ Mid : Sex $=$ Male & -0.0121 & 0.0031 & -3.8598 \\
\hline WordFormFrequency : Sex = Male & 0.0110 & 0.0045 & 2.4410 \\
\hline
\end{tabular}

Independently of short-term frequency, the frequency of the rhyme (LOCALRHYMEFREQRESID) and the frequency of the onset (LOCALONSETFREQRESID) reached significance, with the local frequency of the rhyme emerging as inhibitory, and the local frequency of the onset as facilitatory. Thus two classic poetic devices, end-rhyme and alliteration, emerge with opposite sign. The facilitation for alliteration may arise due to cohort-like preactivation of words sharing word onset, the inhibition for rhyming may reflect an inhibitory neighborhood density effect, or a higher cognitive effect such as attention to rhyme when reading poetry. Crucially, the present experiment shows that in the mixed-modeling framework effects of lexical similarity can be studied not only in the artificial context of controlled factorial experiments, but also in the natural context of the reading of poetry. 
International Journal of Psychological Research, 2009. Vo. 3. No. 2.

ISSN impresa (printed) 2011-2084

ISSN electrónica (electronic) 2011-2079

Third, the present model provides some evidence for sexual differentiation in lexical processing. Ullman and colleagues (Ullman et al., 2002; Ullman, 2007) have argued that females have an advantage in declarative memory, while males might have an advantage in procedural memory. With respect to the superior verbal memory of females (see also Kimura, 2000), note that the negative decelerating effect of long-term frequency (WORDFORMFREQUENCY) is more facilitatory for females than for males: for males, the linear slope of WORDFORMFREQUENCY equals $-0: 0240+0: 0110=$ $-0: 0130$ while for females it is $-0: 0240$. In other words, the facilitation from word frequency is almost twice as large for females compared to males.

There is also some support for an interaction of the morphological complexity (NMORPHEMES) by SEX. While for females, NMORPHEMES has zero slope $(\beta=0.0005, t=$ $0.39)$, males show slightly shorter reading times as the number of morphemes increases $(\beta=0.0005-0.0024=$ $-0.0019, t=-1.90, p<0.05$, one - tailed test).
Baayen, R.H., Milin, P. (2010). Analyzing Reaction Times. International Journal of Psychological Research, 3(2), 12-28.

This can be construed as evidence for a greater dependence on procedural memory for males. The evidence, however, is weaker than the evidence for the greater involvement of declarative memory for females. We will return to these interactions in more detail below.

\section{Random-effects structure}

The random-effects structure of our model is summarized in Table 3. There are three random-effect factors, labeled as 'Groups': WORD, SUBJECT, and POEM. For each, the table lists the standard deviation for the adjustments to the intercepts. ForW ORD and SUBJECT, standard deviations are also listed for the adjustments to two covariates: CHOICERT and AGE to WORD, and NMORPHEMES and WORDFORMFREQUENCY to SUBJECT. (For technical reasons, these covariates were centered, see (Pinheiro \& Bates, 2000).) For each of these two pairs of covariates, correlation parameters have been estimated, two pertaining to correlations of random slopes with random intercepts, and one pertaining to correlations between random slopes.

Table 3: Summary of the random-effects structure in the model fitted to the self-paced reading latencies (number of observations: 275996, groups: Word, 2315; Subject, 326; Poem, 87).

\begin{tabular}{llrrr}
\hline Groups & Name & $\begin{array}{c}\text { Standard } \\
\text { Deviation }\end{array}$ & $\begin{array}{c}\text { Correlations } \\
\text { with Intercept }\end{array}$ & $\begin{array}{c}\text { Correlations } \\
\text { between Slopes }\end{array}$ \\
\hline Word & Intercept & 0.063 & & \\
& CHOICERT & 0.012 & 0.840 & \\
& AGE & 0.001 & -0.905 & -0.779 \\
\hline Subject & Intercept & 0.130 & & \\
& NMORPHEMES & 0.005 & 0.379 & \\
& WORDFORMFREQUENCY & 0.039 & -0.637 & -0.212 \\
\hline Poem & & 0.024 & & \\
\hline Residual & & 0.287 & & \\
\hline
\end{tabular}

In what follows, we first assess whether the large number of parameters ( 7 standard deviations, excluding in this count the residual error, and 6 correlations) is justifiable in terms of a significant contribution to the goodness of fit of the model. Then, we discuss how this random-effects structure can be interpreted. Finally, some conclusions will be given with illustrating the consequences of modeling random effects for the evaluation of the significance of the fixed-effects coefficients.

Evaluation of significance. A sequence of nested models was built, with increased complexity of the randomeffects structure that required the investment of more parameters. For each successive pair of models, the results of a likelihood ratio test were applied, evaluating whether the additional parameters provide a better fit of the model to the data.

The specifications for the lmer function of the random effects for these models are as follows:

$\begin{array}{ll}\begin{array}{ll}\text { random } \\ \text { intercepts only }\end{array} & (1 \mid \text { Word })+(1 \mid \text { Subject })+(1 \mid \text { Poem }) \\ \text { random } & (1 \mid \text { Word })+(0+\text { Age |Word })+ \\ \text { intercepts and } & (0+\text { ChoiceRT|Word })+ \\ \text { slopes } & +(1 \mid \text { Subject }+ \\ & (0+\text { Nmorphemes } \mid \text { Subject })+ \\ & +(1 \mid \text { Poem }) \\ & (1+\text { Age+ChoiceRT|Word })+(1 \mid \text { Subject }) \\ \text { by-word } & +(0+\text { Nmorphemes |Subject })+ \\ \text { correlations } & +(0+\text { WordFormFreq|Subject })+\end{array}$




\begin{tabular}{ll}
\hline & (1| Poem) \\
by-subject & $(1+$ Age+Choi ceRT |Word $)+$ \\
correlations & $(1+$ Nmorphemes +WordFormFreq | Subject $)$ \\
added & $+(1 \mid$ Poem $)$ \\
\hline
\end{tabular}

The first model has random intercepts only, the second has both random intercepts and random slopes, but no correlation parameters. The third model adds in the byword correlation parameters. The fourth model is our final model, with the full random-effects structure in place. In particular, the notation (1+WordFormFreq/Subject) instructs the algorithm to estimate a correlation parameter for the by-subject random intercepts and the by-subject random slopes forW ORDFORMFREQUENCY. Conversely, the notation (1|Subject) + (0+WordFormFreq/Subject) specifies that the by-subject random intercepts should be estimated as independent of the by-subject random slopes for WORDFORMFREQUENCY, i.e., without investing a parameter for their correlation.
Baayen, R.H., Milin, P. (2010). Analyzing Reaction Times. International Joumal of Psychological Research, 3(2), 12-28.

Table 4 summarizes the results of the likelihood ratio tests for the sequence of nested models (including also log-likelihood, aic and bic values). The test statistic follows a chi-squared distribution, with the difference in the number of parameters between the more specific and the more general model as the degrees of freedom. The chi-squared test statistic is twice the ratio of the two log-likelihoods. As we invest more parameters in the random-effects structure (see the column labeled ' $\mathrm{df}$ ', which lists the total number of parameters, including the 34 fixed-effects coefficients), goodness of fit improves, as witnessed by decreas ing values of AIC and BIC, and increasing values of the $\log$ likelihood. For each pairwise comparison, the increase in goodness of fit is highly significant. Other random slopes were also considered, but were not supported by likelihood ratio tests.

Table 4: Likelihood ratio tests comparing models with increasingly complex random-effects structure: a model with random intercepts only, a model with by-subject and by-word random intercepts and slopes, but no correlation parameters, a model adding in the by-word correlation parameters, and the full model with also by-subject correlation parameters. (df: the number of parameters in the model, including the coefficients of the fixed-effect part of the model.)

\begin{tabular}{lrrrrrrr}
\hline & df & AIC & BIC & log-likelihood & $\chi^{2}$ & $\mathrm{df}_{z^{2}}$ & $\mathrm{p}$ \\
\hline random intercepts only & 38 & 104893 & 105293 & -52408 & & & \\
random intercepts and slopes & 42 & 101103 & 101545 & -50509 & 3797.9 & 4 & $\ll 0.0001$ \\
by-word correlations added & 45 & 101029 & 101503 & -50470 & 79.4 & 3 & $\ll 0.0001$ \\
by-subject correlations added & 48 & 100880 & 102386 & -50392 & 155.2 & 3 & $\ll 0.0001$ \\
\hline
\end{tabular}

Interpretation of the random effects structure. Given that the present complex random-effects structure is justified, the question arises how to interpret the parameters. Scatterplot matrices, as shown in Figure 10, often prove to be helpful guides. The left matrix visualizes the random effects structure for words, the right matrix that for subjects, where in the left matrix each dot represents a word, and in the right matrix a dot represents a subject. For each pair of covariates, the blups (the best linear unbiased predictors) for the words (left) and subjects (right) are shown. The blups can be understood as the adjustments required to the population estimates of intercept and slopes to make the model precise for a given word or subject. Correlational structure is visible in all panels, as expected given the 6 correlation parameters in the model specification.

First consider the left matrix in Figure 10. It shows much tighter correlations, which arise because in this experiment words were partially nested under poem and subject. With limited information on the variability across subjects and in respect to words' processing difficulty, estimated correlations are tight. In the first row of the left panel, differences in the intercept (on the vertical axis) represent differences in the baseline difficulty of words. Easy words (with short self-paced reading latencies) have downward adjustments to the intercept, difficult words (with long latencies) have upward adjustments. These adjustments for the intercept correlate positively with the adjustments for the slope of the CHOICERT, the time required for a subject to complete the final multiple choice question about the number of poems read on a yearly basis. The estimated population coefficient for this predictor is $\beta=0.0543$ (c.f., Table 2): Careful, slow respondents are also slow and careful readers. Across words, the adjustments to this population slope for CHOICE RT give rise to word-specific slopes ranging from 0.022 to 0.109 . The positive correlation of the by-word intercepts and these by-word slopes indicates that for difficult words (large positive adjustments to the intercept), the difference between the slow and fast responders to the multiple choice question is more pronounced (as reflected by upward adjustments resulting in even steeper positive slopes). Conversely, for words with the larger downward adjustments to the slope of CHOICERT, the easy words, the difference between the slow (presumably careful and precise) and fast (more superficial) responders is attenuated. 
Figure 10. Visualization of the correlation structure of the random intercepts and slopes for WORD (left) and SUBJECT (right) by means of scatterplot matrices.

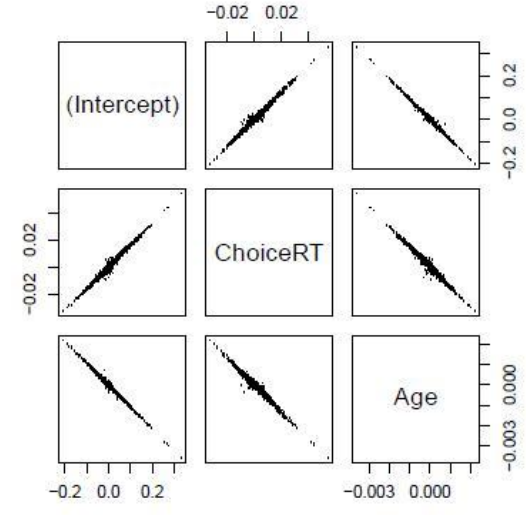

Next, from the fixed-effects part of the model, we know that older subjects are characterized by longer reaction times $(\beta=0,0034)$. The effect of AGE is not constant across words, however. For some words (with maximal downward adjustment for AGE), the effect of AGE is actually cancelled out, while there are also words (with positive adjustments) for which the effect of AGE is felt even more strongly. The negative correlation for the byword adjustments to the slope for AGE and the by-word adjustments to the intercept indicates that it is for the more difficult words that the effect of Age disappears, and that it is for the easier words that the effect of Age manifests itself most strongly.

The negative correlation for AGE and CHOICE RT indicates that the words for which greater AGE leads to the longest responses are also the words for which elongated choice behavior has the smallest processing cost. The three correlations considered jointly indicate that the difficult words (large positive adjustments to the intercept) are the words where careful choice behavior is involved, but not so much AGE, whereas the easy words (downward adjusted intercepts) are those where differences in age are most clearly visible, but not choice behavior.

The scatterplot matrix in the right panel of Figure 10 visualizes the less tight correlational structure for the bysubject adjustments to intercept and slopes. The adjustments to the intercept position subjects with respect to the average response time. Subjects with large positive blups for the intercept are slow subjects, those with large negative blups are fast responders.

The population slope for the count of morphemes in the word (NMORPHEMES) is 0 for females and -0.002 for males. By-subject adjustments range from -0.008 to +0.008 , indicating substantial variability exceeding the group difference. Subjects with a more negative slope for

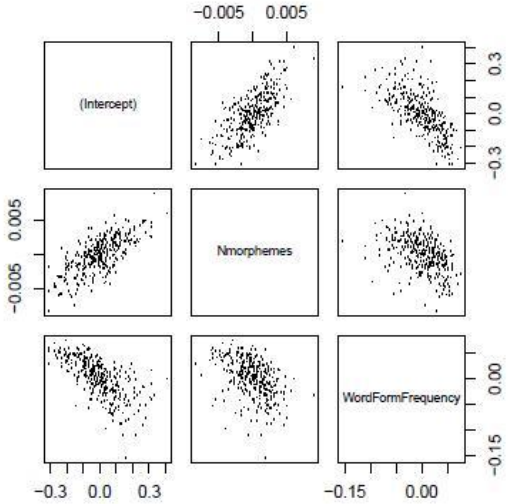

NMORPHEMES tend to be faster subjects, those with a positive slope tend to be the slower subjects.

The linear coefficient of WORDFORMFREQUENCY estimated for the population is -0.024 for females and -0.013 for males. For different female subjects, addition of the adjustments results in slopes ranging from -0.178 to 0.051 , for males, this range is shifted upwards by 0.011 . For most subjects, we have facilitation, but for a few subjects there is no effect or perhaps even an lantifrequency" effect. The negative correlation for the bysubject adjustments to the intercept and to the slope of frequency indicates that faster subjects, with downward adjustments for the intercept, are characterized by upward adjustment for WORDFORMFREQUENCY slopes. Hence, these fast subjects have reduced facilitation or even inhibition from WordFormFrequency. Conversely, slower subjects emerge with stronger facilitation.

Interestingly, the correlation of the adjustments for WORDFORMFREQUENCY and NMORPHEMES is negative, indicating that subjects who receive less facilitation from frequency obtain more facilitation from morphological complexity and vice versa.

Consequences for the fixed-effects coefficients. Careful modeling of the correlational structure of the random effects is important not only for tracing cognitive trade-offs such as observed for storing (W ORDFORMFREQUENCY) and parsing (NMORPHEMES), it is also crucial for the proper evaluation of interactions with fixed-effect factors partitioning subjects or items into subsets. Consider the interaction of SEX by WORDFORMFREQUENCY and SEX by NMORPHEMES. In the full model, the former interaction receives good support with $t=2.44$, while the latter interaction fails to reach significance $(t=-1.90)$. However, in models having only random intercepts for subjects, $t-v a l u e s$ increase to 7.73 and -1.99 respectively. 
International Journal of Psychological Research, 2010. Vo. 3. No. 2. ISSN impresa (printed) 2011-2084

ISSN electrónica (electronic) 2011-2079

These models are not conservative enough, however. They overvalue the interactions in the fixed-effects part of the model, while falling short with respect to their goodness of fit, which could have been improved substantially by allowing into the model individual differences between subjects with respect to WORDFORMFREQUENCY and NMORPHEMES. In other words, when testing for interactions involving a group variable such as SEX, the interaction should survive inclusion of random slopes, when such random slopes are justified by likelihood ratio tests. In the present example, the interaction of SEX by WORDFORMFREQUENCY survives inclusion of random slopes for WORDFORMFREQUENCY, but the interaction with NMORPHEMES does not receive significant support.

\section{Model Criticism}

To complete the analysis, we need to examine our model critically with respect to potential distortions due to outliers. Before modeling, the data were screened for artificial responses (such as those generated by subjects holding the spacebar down to skip poems they did not like), but no outliers were removed. As the presence of outliers may cause stress in the model, we removed datapoints with absolute standardized residuals exceeding 2.5 standard deviations (2.7\% of the data). The trimmed model was characterized by residuals that approximated normality more closely, as expected.

Model criticism can result in three different outcomes for a given coefficient. A coefficient that was significant may no longer be so after trimming. If we recall the difference between the outliers and the extreme values, in this case it is likely that a few extreme values are responsible for the effect. Given that the vast majority of data points do not support the effect, we then conclude that there is no effect. Conversely, a coefficient that did not reach significance may be significant after model criticism. In that case, a small number of outliers was probably masking an effect that is actually supported by the majority of data points. In this case we conclude there is a significant effect. Data trimming may also not affect the significance of a predictor in case the influential values have little leverage with respect to that particular predictor.

For the present data, model criticism did lead to a revision of the coefficients for the interactions of SEX by NMORPHEMES and SEX by WORDFORMFREQUENCY. For both, evidence for a significant interaction increased. The tvalue for the coefficient of the interaction of SEX by WORDFORMFREQUENCY increased from 2.44 to 2.71 , and the coefficient for SEX by NMORPHEMES showed absolute increase from -1.90 to -2.77 . We note that trimming does not automatically result in increased evidence for significance. For instance, the support for the predictor POEMSREADYEARLY decreased after trimming, as indicated
Baayen, R.H., Milin, P.(2010). Analyzing Reaction Times. International Joumal of Psychological Research, 3(2), 12-28.

by the t-value, with decreased absolute values from -1.85 to -1.75 .

In the light of these considerations, we conclude that this data set provides evidence supporting the hypothesis of Ullman and colleagues that the superior declarative memory of women affords stronger facilitation from word frequency, whereas males show faster processing of morphologically complex words, possibly due to a greater dependence on procedural memory. Although these differences emerge as significant, over and above the individual differences that are also significant, they should be interpreted with caution, as the effect sizes are small. The facilitation from WORDFORMFREQUENCY, evaluated by comparing the effects for the minimum and maximum word frequencies, was $67 \mathrm{~ms}$ for females and 40 $\mathrm{ms}$ for males; an advantage of $27 \mathrm{~ms}$ for females. The advantage in morphological processing for males is $16 \mathrm{~ms}$ (a $10 \mathrm{~ms}$ advantage for males compared to a $6 \mathrm{~ms}$ disadvantage for females).

\section{CONCLUDING REMARKS}

The approach to the statistical analysis of reaction time data that we have outlined is very much a practical one, seeking to understand the structure of experimental data without imposing a-priori assumptions about the distribution of the dependent variable, the nature and source of the influential values, the mechanisms underlying temporal dependencies, or the functional shape of regressors. While anticipating that more specific wellvalidated theory-driven assumptions will allow for improvements at all stages of analysis, we believe that many of the classical methodological concerns can be addressed more effectively and more parsimoniously in the mixed-modeling framework. Furthermore, what we hope to have shown is that mixed-modeling offers new and exciting analytical opportunities for understanding many of the different forces that simultaneously shape the reaction times, which inform theories of human cognition.

\section{REFERENCES}

Baayen, R. H. (2007). Storage and computation in the mental lexicon. In G. Jarema \& G. Libben (Eds.), The mental lexicon: Core perspectives. Oxford: Elsevier.

Baayen, R. H. (2010). languager: Data sets and functions with "analyzing linguistic data: A practical introduction to statistics". [Computer software manual]. Available from http://CRAN.Rproject. org/package=languageR package version 1.0)

Baayen, R. H., Davidson, D. J., \& Bates, D. (2008). Mixedeffects modeling with crossed random effects for

International Journal of Psychological Research 
International Journal of Psychological Research, 2009. Vo. 3. No. 2.

ISSN impresa (printed) 2011-2084

ISSN electrónica (electronic) 2011-2079

subjects and items. Journal of Memory and Language, 59, 390-412.

Baayen, R. H., Feldman, L., \& Schreuder, R. (2006). Morphological inuences on the recognition of monosyllabic monomorphemic words. Journal of Memory and Language, 53, 496-512.

Baayen, R. H., Wurm, L. H., \& Aycock, J. (2007). Lexical dynamics for low-frequency complex words. a regression study across tasks and modalities. The Mental Lexicon, 2, 419-463.

Balling, L., \& Baayen, R. H. (2008). Morphological effects in auditory word recognition: Evidence from Danish. Language and Cognitive Processes, 23, 1159-1190.

Bates, D., \& Maechler, M. (2009). lme4: Linear mixedeffects models using s4 classes [Computer software manual]. Available from http: / / CRAN. R-project . org/package=lme4 (R package version 0.999375-32)

Beaudoin, N. (1999). Fourier transform deconvolution of noisy signals and partial savitzky-golay filtering in the transformed side. In Proceedings of the 12th conference on vision interface (pp. 405-409). Trois-Rivieres, Canada: Universite du Quebec a Trois-Rivieres

Bertram, R., Kuperman, V., \& Baayen, R. (2010). The hyphen as a segmentation cue in compound processing: It's getting better all the time. submitted.

Boulinguez, P., \& Barthelemy, S. (2000). Influence of the movement parameter to be controlled on manual RT asymmetries in right-handers. Brain and Cognition, 44 (3), 653-661.

Breukers, C. (2006). 25 jaar nederlandstalige poezie $1980\{2005$ in 666 en een stuk of wat gedichten. Nijmegen: BnM Publishers.

Broadbent, D. (1971). Decision and stress. New York: Accademic Press.

Clark, H. (1973). The language-as-_xed-e_ect fallacy: A critique of language statistics in psychological research. Journal of Verbal Learning and Verbal Behavior, 12, 335-359.

Cornwell, T., \& Bridle, A. (1996). Deconvolution tutorial. Available from http://www.cv.nrao.edu/ rabridle/deconvol/deconvol .html

Cornwell, T., \& Evans, K. (1985). A simple maximum entropy deconvolution algorithm. Astronomy and Astrophysics, $143,77-83$.

De Vaan, L., Schreuder, R., \& Baayen, R. H. (2007). Regular morphologically complex neologisms leave detectable traces in the mental lexicon. The Mental Lexicon, 2 , 1-23.

Donders, F. (1868/1969). On the speed of mental processes. Acta Psychologica, 30 , 412-431. (Translated by W. G. Koster)

International Journal of Psychological Research
Baayen, R.H., Milin, P. (2010). Analyzing Reaction Times. International Journal of Psychological Research, 3(2), 12-28.

Forster, K., \& Dickinson, R. (1976). More on the languageas-fixed effect: Monte-Carlo estimates of error rates for F1, F2, F0, and minF0. Journal of Verbal Learning and Verbal Behavior, 15 , 135-142.

Harrell, F. (2001). Regression modeling strategies. Berlin: Springer.

Hocking, R. R. (1996). Methods and applications of linear models. regression and the analysis of variance. New York: Wiley.

Jaeger, T. (2008). Categorical data analysis: Away from ANOVAs (transformation or not) and towards logit mixed models. Journal of Memory and Language, 59 (4), 434-446.

Keppel, G., \& Sauey Jr., W. (1980). Introduction to design and analysis. San Francisco: W. H. Freeman and Company.

Kimura, D. (2000). Sex and cognition. Cambridge, MA: The MIT press.

Kuperman, V., Schreuder, R., Bertram, R., \& Baayen, R. H. (2009). Reading of multimorphemic Dutch compounds: towards a multiple route model of lexical processing. Journal of Experimental Psychology: HPP, 35 , 876-895.

Lemhoefer, K., Dijkstra, A., Schriefers, H., Baayen, R., Grainger, J., \& Zwitserlood, P. (2008)

Native language inuences on word recognition in a second language: a megastudy. Journal of Experimental Psychology: Learning, Memory, and Cognition, 34, 12-31.

Luce, R. (1986). Response times. New York: Oxford University Press.

MacDonald, S., Nyberg, L., Sandblom, J., Fischer, H., \& Backman, L. (2008). Increased response-time variability is associated with reduced inferior parietal activation during episodic recognition in aging. Journal of Cognitive Neuroscience, 20 (5), 779-787.

Milin, P., Filipovic Durdevic, D., \& Moscoso del Prado Martín, F. (2009). The simultaneous effects of inflectional paradigms and classes on lexical recognition: Evidence from serbian. Journal of Memory and Language, 60 (1), 50-64.

Milin, P., Kuperman, V., Kosti_c, A., \& Baayen, R. (2009). Words and paradigms bit by bit: An informationtheoretic approach to the processing of inection and derivation. In J. Blevins \& J. Blevins (Eds.), Analogy in grammar: Form and acquisition (pp. 214-252). Oxford: Oxford University Press.

Miller, J., Daly, J., Wood, M., Roper, M., \& Brooks, A. (1997). Statistical power and its subcomponents missing and misunderstood concepts in empirical software engineering research. Journal of Information and Software Technology, 39 , 285295.

Piéron, H. (1920). Nouvelles recherches sur l'analyse du temps de latence sensorielle et sur la loi qui relie 
International Journal of Psychological Research, 2010. Vo. 3. No. 2.

ISSN impresa (printed) 2011-2084

ISSN electrónica (electronic) 2011-2079

ce temps a l'intensit_e de l'excitation. Année Psychologique, 22 , 58-142.

Pinheiro, J. C., \& Bates, D. M. (2000). Mixed-e_ects models in S and S-PLUS. New York: Springer.

Quen_e, H., \& Bergh, H. van den. (2008). Examples of mixed-effects modeling with crossed random effects and with binomial data. Journal of Memory and Language, 59 (4), 413-425.

Raaijmakers, J., Schrijnemakers, J., \& Gremmen, F. (1999). How to deal with "the language as fixed effect fallacy": common misconceptions and alternative solutions. Journal of Memory and Language, 41 , 416-426.

Ratcliff, R. (1979). Group reaction time distributions and an analysis of distribution statistics. Psychological Bulletin, 86, 446-461.

Ratcliff, R. (1993). Methods for dealing with reaction time outliers. Psychological Bulletin, 114, 510-532.

Robinson, E. (1934). Work of the integrated organism. In C. Murchison (Ed.), Handbook of general experimental psychology (pp. 571-650). Worcester: Clark University Press.

Rouder, J., Lu, J., Speckman, P., Sun, D., \& Jiang, Y. (2005). A hierarchical model for estimating response time distributions. Psychonomic Bulletin \& Review, 12 (2), 195-223.

Rouder, J., \& Speckman, P. (2004). An evaluation of the vincentizing method for forming group-level response time distributions. Psychonomic Bulletin \& Review, 11 (3), 419-427.

Sanders, A. (1998). Elements of human performance: Reaction processes and attention in human skill. Mahwah, New Jersey: Lawrence Erlbaum.

Sirkin, M. R. (1995). Statistics for the social sciences. London: Sage.

Tabak, W., Schreuder, R., \& Baayen, R. H. (2010a). Inection is not Iderivational": Evidence from word naming. Manuscript submitted for publication.

Tabak, W., Schreuder, R., \& Baayen, R. H. (2010b). Producing inected verbs: A picture naming study. The Mental Lexicon.

Taylor, T. E., \& Lupker, S. J. (2001). Sequential e_ects in naming: A time-criterion account. Journal of Experimental Psychology: Learning, Memory and Cognition, 27 , 117-138.

Ullman, M. (2007). The biocognition of the mental lexicon. The Oxford handbook of psycholinguistics, 267286.

Ullman, M., Estabrooke, I., Steinhauer, K., Brovetto, C., Pancheva, R., Ozawa, K., et al. (2002). Sex differences in the neurocognition of language. Brain and Language, 83, 141-143.

Van Zandt, T. (2000). How to _t a response time distribution. Psychonomic Bulletin and Review, 7, 424-465.
Baayen, R.H., Milin, P. (2010). Analyzing Reaction Times. International Joumal of Psychological Research, 3(2), 12-28.

Van Zandt, T. (2002). Analysis of response time distributions. In J. Wixted \& H. Pashler (Eds.), Stevens' handbook of experimental psychology, volume 4: Methodology in experimental psychology (pp. 461\{516). New York: Wiley.

Wagenmakers, E., van der Maas, H., \& Grasman, R. (2008). An EZ-diffusion model for response time and accuracy. Psychonomic Bulletin \& Review, 14 (1), 3-22.

Welford, A. (1977). Motor performance. In J. Birren \& K. Schaie (Eds.), Handbook of the psychology of aging (pp. 450\{496). New York: Van Nostrand Reinhold.

Welford, A. (1980). Choice reaction time: Basic concepts. In A. Welford (Ed.), Reaction times (pp. 73-128). New York: Accademic Press.

Whelan, R. (2008). E_ective analysis of reaction time data. The Psychological Record, 58 , 475-482.

Wood, S. N. (2006). Generalized additive models. New York: Chapman \& Hall/CRC. 